\title{
MASTER
}

\section{A Two-Dimensional Relaxation Program for Systems with Inhomogeneous Permeability}
W. E. Deeds
C. V. Dodd

\section{OAK RIDGE NATIONAL LABORATORY}




\section{DISCLAIMER}

This report was prepared as an account of work sponsored by an agency of the United States Government. Neither the United States Government nor any agency Thereof, nor any of their employees, makes any warranty, express or implied, or assumes any legal liability or responsibility for the accuracy, completeness, or usefulness of any information, apparatus, product, or process disclosed, or represents that its use would not infringe privately owned rights. Reference herein to any specific commercial product, process, or service by trade name, trademark, manufacturer, or otherwise does not necessarily constitute or imply its endorsement, recommendation, or favoring by the United States Government or any agency thereof. The views and opinions of authors expressed herein do not necessarily state or reflect those of the United States Government or any agency thereof. 


\section{DISCLAIMER}

Portions of this document may be illegible in electronic image products. Images are produced from the best available original document. 


\section{Printed in the United States of America. Available from National Technical Information Service \\ U.S. Department of Commerce \\ 5285 Port Royal Road, Springfield, Virginia 22161 \\ Price: Printed Copy \$4.00; Microfiche \$2.25}

This report was prepared as an account of work sponsored by the United States Government. Neither the United States nor the Energy Research and Development Administration/United States Nuclear Regulatory Commission, nor any of their employees, nor any of their contractors, subcontractors, or their employees, makes any warranty, express or implied, or assumes any legal liability or responsibility for the accuracy, completeness or usefulness of any information, apparatus, product or process disclosed, or represents that its use would not infringe privately owned rights. 
ORNL/TM-5333

UC-20 - Controlled Thermonuclear

Processes and Plasma Physics

Contract No. W-7405-eng-26

METALS AND CERAMICS DIVISION

A TWO-DIMENSIONAL RELAXATION PROGRAM FOR SYSTEMS

WITH INHOMOGENEOUS PERMEABILITY

W. E. Deeds and C. V. Dodd

JUNE 1976

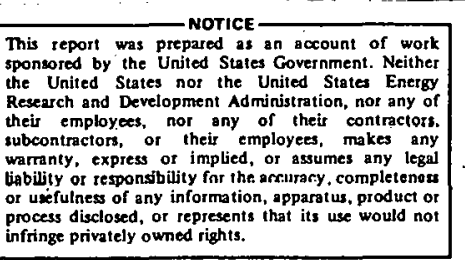

NOTICE This document contains information of a preliminary nature and was prepared primarily for internal use at the Oak Ridge National Laboratory. It is subject to revision or correction and therefore does not represent a final report.

\footnotetext{
OAK RIDGE NATIONAL LABORATORY

Oak Ridge, Tennessee 37830

operated by

UNION CARBIDE CORPORATION

for the

ENERGY RESEARCH AND DEVELOPMEN'T ADMINISTRATION
} 


\section{THIS PAGE \\ WAS INTENTIONALLY \\ LEFT BLANK}


CONTENTS

Page

ABSTRACT . . . . . . . . . . . . . . . . . . . 1

INTRODUCTION . . . . . . . . . . . . . . . . . 1

THEORY . . . . . . . . . . . . . . . . . . . . 3

DESCRIPTION OF THE PROGRAM . . . . . . . . . . . . . . 8

DETAILED DESCRIPTION OF THE RELAX PROGRAM . . . . . . . . . . 13

Main Control Routine .. . . . . . . . . . . . . 13

LATT Subroutine . . . . . . . . . . . . . . . 14

COARSE Subroutine . . . . ............. 15

FINE Subroutine................... 16

OUTPUT Subroutine................. 16

DISCUSSION OF MODIFICATIONS TO THE PROGRAM . . . . . . . . . 17

USING THE PROGRAM ON A TIME-SHARING COMPUTER........ .19 


\title{
A TWO-DIMENSIONAL RELAXATION PROGRAM FOR SYSTEMS WITH INHOMOGENEOUS PERMEABILITY*
}

W. E. Deeds ${ }^{\dagger}$ and C. V. Dodd

\begin{abstract}
A computer program is presented and explained which will solve axially symmetric eddy-current problems, including those with permeable media present. An unusual feature is the combination of coarse and fine lattices, which permit rapid relaxation of coarse lattices in homogeneous regions to be combined with more accurate calculations using a fine lattice in the transition regions where the permeability is varying. Although the actual program listed is restricted to coils encircling a coaxial metal rod, the program can be modified to include any axially symmetric configuration.
\end{abstract}

\section{INTRODUCTION}

Relaxation methods have been used for solving many types of problems for many years. They have been used in eddy-current calculations at Oak Ridge National Laboratory since 1963.1,2,3 The earlier calculations gave good results, except when ferromagnetic materials were present, in which case the large permeability changes at the boundaries gave unreliable results.

\footnotetext{
*Funding provided by the Superconducting Magnet Development Program, Thermonuclear D1vision, Oak Ridge National Laboratory.

${ }^{\dagger}$ Consultant from the University of Tennessee, Knoxville.

${ }^{1}$ C. V. Dodd, "Eddy-Current Impedance Calculated by a Relaxation Method," pp. 300-314 in Proceedings of the Symposium on Physics and Nondestructive Testing, Southwest Research Institute, San Antonio, Texas, 1963.

C. V. Dodd, Solutions to Electromagnetic Induction Problems, ORNL-TM-1842 (June 1967). Ph.D. Thesis, The University of Tennessee. 3

J. Nelson Tunstall and C. V. Dodd III, A Computer Progrom to Solve EddyCurrent. Problems, K-1740 (April 8, 1968).
} 
There are two possible ways of treating such large permeability changes. One way is to treat the boundary points as a separate set, satisfying conditions different from the points inside the homogeneous regions. The other way is to introduce an extrafine lattice in the transition region, so that the change of the permeability in one lattice spacing remains small. The former method appears simpler at first, but the boundary conditions become quite complicated in three dimensions, since the normal and tangential components of the fields are treated differently, and the slope of the boundary is important. Since threedimensional calculations were a further ubjeclive, tlie second approuch seemed better. The extratine lattice in the cranslitun itylunis iust satisty the equations for an Inhomogeneous medium, while the various homogeneous regions can use the equations for homogeneous media and have relatively coarse lattices.

The coarse lattices in the homogeneous regions must overlap the fine lattices sufficiently to allow them to affect each other as they are relaxed alternately, using as boundary conditions the values computed for the other lattice in the previous iteration. At points in the fine lattice boundary which are located between the coarse lattice boundary points, interpolated values of the vector potential can be used.

In order to conserve memory storage capacity in the computer, a relaxation procedure was used in which the newly computed value of the vector potential at a point immediately replaced the value from the previous iteration and was used in subsequent calculations in the current stage of the iteration. This made it unnecessary to store two complete sets of values for the lattices, one for the previous iteration and one for the present iteration. This method gives an unsymmetrical approach to the converged values, but it converges at leasl as fast as the (not overrelaxed) conventional system, and it does not.appear to cause duy instability or oscillation.

Another change in the present program from thiose previously used at Oak Ridge National Laboratory is in the use of "symmetrical" derivatives in the finite difference approximations, rather than the unsymmetrical ones used previously. This did not appear to make any difference in the speed of convergence or in any of the results, but the equations are more symmetrical. 
The results obtained using this program for a coil encircling a rod, as shown in Fig. 1, have been compared with the results of an analytical solution which has been experimentally verified to within about 1\%. Using a moderately fine mesh, the program runs for about 5 min on an IBM 360 model 91, is within about $10 \%$ of the analytical solution when the rod has unit permeability, and is within about $30 \%$ when the rod has a permeability of 4 .

\section{THEORY}

The vector Helmholtz equation for the vector potential in the Coulomb gauge $(\nabla \cdot \vec{A}=0)$ is.

$$
\nabla^{2} \vec{A}-\mu \sigma \frac{\partial \vec{A}}{\partial t}-\mu \varepsilon \frac{\partial^{2} \vec{A}}{\partial t^{2}}=-\mu \vec{J}+\mu \nabla\left(\frac{1}{\mu}\right) \times(\nabla \times \vec{A})
$$

If we neglect the displacement current term at induction frequencies and assume sinusoidal time-dependence of the driving current and vector potential, then. (1) reduces to

$$
\nabla^{2} \overrightarrow{\mathrm{A}}=j \omega \mu \sigma \overrightarrow{\mathrm{A}}-\mu \vec{J}_{\text {ext }}+\mu \nabla\left(\frac{1}{\mu}\right) \times(\nabla \times \overrightarrow{\mathrm{A}})
$$

If the driving current density $\vec{J}_{\text {ext }}$ has only a $\theta$ component in cylindrical coordinates and all conductors are symmetrical about the axis, then $\vec{A}$ also has only a single component, $A_{\theta} \equiv A$, which satisfies the scalar equation

$$
\begin{aligned}
\frac{\partial^{2} A}{\partial r^{2}}+\frac{1}{r} \frac{\partial A}{\partial r}+\frac{\partial^{2} A}{\partial z^{2}}-\frac{A}{r^{2}}+\mu\left[\frac{\partial(1 / \mu)}{\partial r}\left(\frac{1}{r} \frac{\partial r A}{\partial r}\right)+\frac{\partial(1 / \mu)}{\partial \dot{z}}\right. & \left.\frac{\partial A}{\partial z}\right] \\
& =j \omega \mu \sigma A-\mu J_{\theta} .
\end{aligned}
$$

The finite difference. approximations to the various derivatives are as follows: 
ORNL- DWG 75-18026

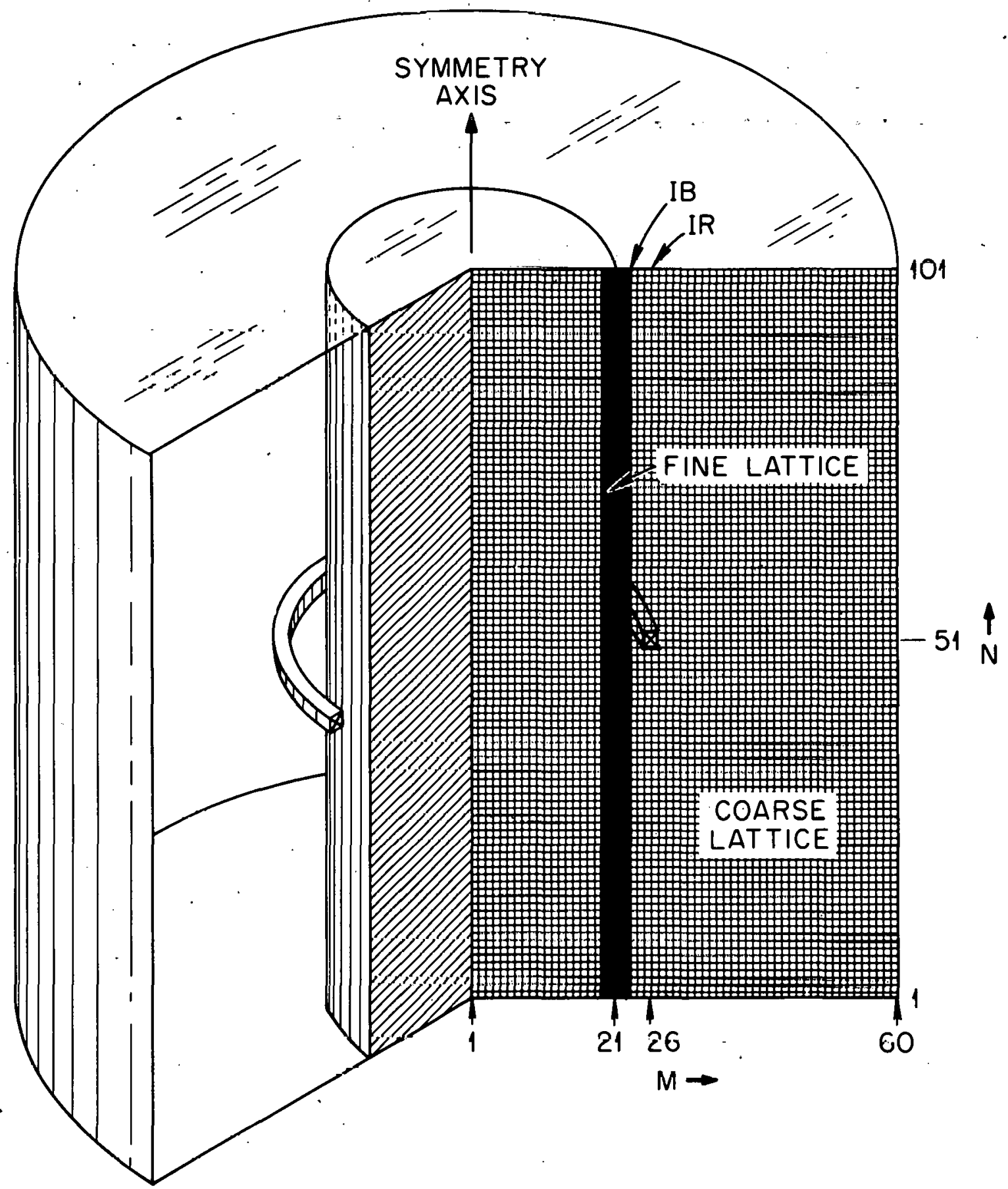

Fig. 1. Relaxation lattice for encircling coil. 


$$
\begin{aligned}
& \frac{\partial^{2} A}{\partial r^{2}} \doteq \frac{A_{p+a, z}+A_{r-a, z}-2 A_{r, z}}{a^{2}} \\
& \frac{1}{r} \frac{\partial A}{\partial r} \doteq \frac{A_{r+a, z}-A_{r-a, z}}{2 a r}, \\
& \frac{\partial^{2} A}{\partial z^{2}} \doteq \frac{A_{r, z+a}+A_{r, z-a}-2 A_{r, z}}{a^{2}}, \\
& \mu \frac{\partial(1 / \mu)}{\partial r} \doteq\left(\frac{\mu_{r, z}}{\mu_{r+a, z}}-\frac{\mu_{r, z}}{\mu_{r-a, z}}\right) / 2 a, \\
& \mu \frac{\partial(1 / \mu)}{\partial z} \doteq\left(\frac{\mu_{r, z}}{\mu_{r, z+a}}-\frac{\mu_{r, z}}{\mu_{r, z-\alpha}}\right) / 2 a, \\
& \frac{1}{r} \frac{\partial(r A)}{\partial r} \doteq \frac{(r+a) A_{r+a, z}-(r-a) A_{r-a, z}}{2 a r}, \\
& \frac{\partial A}{\partial Z} \doteq \frac{A_{r, z+a}-A_{r, z-a}}{2 a} .
\end{aligned}
$$

When these approximations are put into Eq. (3) and the result is solved for $A$ at $(r, z)$, we get the relaxation algorithm for an inhomogeneous medium: 


$$
\begin{aligned}
& A_{r, z}=\left\{\left[1+\frac{a}{2 r}+\left(\frac{r+a}{4 r}\right)\left(\frac{\mu_{r, z}}{\mu_{r+a, z}}-\frac{\mu_{r, z}}{\mu_{r-a, z}}\right)\right] A_{r+a, z}\right. \\
& +\left[1-\frac{a}{2 r}-\left(\frac{r-a}{4 r}\right)\left(\frac{\mu_{r, z}}{\mu_{r+a, D}}-\frac{\mu_{r, z}}{\mu_{r, a_{j} \delta}}\right)\right] A_{r-a, z} \\
& +\left[1+\frac{1}{4}\left(\frac{\mu_{r, z}}{\mu_{r, 3+a}}-\frac{\mu_{r, z}}{\mu_{r, 3-a}}\right)\right] A_{r, z+a}
\end{aligned}
$$

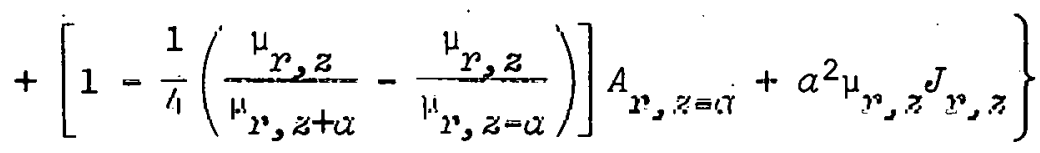

$$
\begin{aligned}
& \div\left[4+(a / r)^{2}+j \omega \mu_{r_{,}, z^{\sigma}, z} a^{2}\right] .
\end{aligned}
$$

In a homogeneous medium, the permeabilities'are all the same, and Eq. (11) reduces to

$$
\begin{array}{r}
A_{r, z}=\left\{\left[1+\left(a / 2 r^{r}\right)\right] A_{r+a, z}+[1-(a / 2 r)] \dot{A}_{r-a, z}+\dot{A}_{r, z+a}+\dot{A}_{r, z-a}\right. \\
\left.+a^{2} \mu_{r, z}{ }_{r, z}\right\} \div\left[4+\left(a / r^{\prime}\right)^{2}+j \omega \mu_{r, z} \sigma_{r, z} a^{2}\right] .
\end{array}
$$

It is evident from Eq. (12) that $a^{2} \mu_{e} T$ must have the same dimensions as the vector potential, $A$. Since $a$ is the lattice spacing and $J$ is the driving current density, we see that $a^{2} J$ is the driving current through one square of the lattice. If $N_{q}$ is the number of turns in the coil and $I_{q}$ is the current in each turn, then

$$
I_{0}=N_{q} I_{q}=\text { total current in the coil. }
$$

If $n$ is the number of lattice spacings in the mean coil radius, $\bar{R}$, then $n=\bar{R} / a$. If $R_{2}-R_{1}=\left(r_{2}-r_{1}\right) / \bar{R}=$ normalized radial dimension of 
the coil, and if $L_{2}-L_{1}=\left(\ell_{2}-\ell_{1}\right) / \bar{R}=$ normalized axial length of the coil, then

$$
\begin{aligned}
n^{2}\left(R_{2}-R_{1}\right)\left(L_{2}-L_{1}\right) & =\left(\frac{\bar{R}}{\bar{a}}\right)^{2}\left(\frac{r_{2}-r_{1}}{\bar{R}}\right)\left(\frac{\ell_{2}-\ell_{1}}{\bar{R}}\right)=\left(\frac{r_{2}-r_{1}}{a}\right)\left(\frac{\ell_{2}-\ell_{1}}{a}\right) \\
& =\text { number of lattice points in coil cross section } .
\end{aligned}
$$

Therefore

$$
\mathrm{A} \propto \mu a^{2} J=\frac{\mu N I_{q}}{n^{2}\left(R_{2}-R_{1}\right)\left(L_{2}-L_{1}\right)} .
$$

Equation (13) is the relationship by which the vector potential varies with the various scaling parameters: permeability $\mu$, coil turns $N_{q}$, coil current $I_{q}$, coil mean radius in lattice spacings $n$, and the normalized cross-sectional area $\left(R_{2}-R_{1}\right)\left(L_{2}-L_{1}\right)$.

The other quantities, such as forces, heating, etc., which depend upon the vector potential, have their scaling factors given elsewhere. 4 Equations $(4)-(10)$ are called symmetrical derivatives, because they are centered at the point $(r, z)$, in contrast to a one-sided derivative, such as

$$
\left(\frac{\partial A}{\partial x^{2}}\right)_{\text {one-sided }}=\frac{A_{\mathrm{q} 4 u, z}-A_{w, z}}{a},
$$

which gives slightly different equations in place of (11) and (12). The differences are generally small, except near the axis or at boundaries where $A$ changes rapidly.

C. V. Dodd and W. E. Deeds, Scaling Relations for Eddy Current Pheriomena, ORNL-5077 (November 1975). 
The computer program uses Eq. (12) for the coarse lattice in the homogeneous regions, such as the metals, coils, and air, and uses Eq. (11) for the fine lattices at the boundaries between homogeneous regions, where the values of $\mu$ and $\sigma$ are changing. The program alternately steps through the coarse and fine lattices, using the values just computed for the other lattice as boundary values in the relaxation of the lattice being computed.

With modifications, the program can be used for any axially symmetric distribution of coils and conductors. The running time is of the order of a few minutes on an IBM 360 model 91 for an array of about 10,000 lattice pointa, roughly half in the coarse lattice and half in the fine lattice. The layout of the coarse and fine lattices is shown in Fig. 2; the variation of the conductivity with the radius is shown at the bottom.

The quantity SUM is the sum of the absolute values of the changes of vector potential from one iteration to the next and thus is a measure of the convergence of the vector potential to the limiting values. However, the value of the vector potential at each point may oscillate before settling down to a monotonic approach. In Figs. 3 and 4 are shown curves of the variation with the number of iterations of the magnitude and phase of the vector potential at the coarse lattice points marked with circles in Fig. 2. Note that the points nearer the coil source receive the signal sooner and converge faster. The signal will propagate through the lattice at the rate of one lattice spacing per iteration. Hence, it will take of the order of 150 iterations for the signal to reach the boundaries and start back. Since a number of reflections back and forth are required to reach a steady state, we see that it is not surprising that the number of iterations required is large.

\section{DESCRIPTION OF THE PROGRAM}

There is a main control program, which defines and initializes several quantities used in the calculations and controls the switching from coarse to fine lattices and back, as well as to the output subroutine. The first subroutine, called only once, is named LATT. It sets up the coarse and fine lattices and initializes the values of the vector potential at all lattice points to zero. 
ORNL-DWG 75-18025R

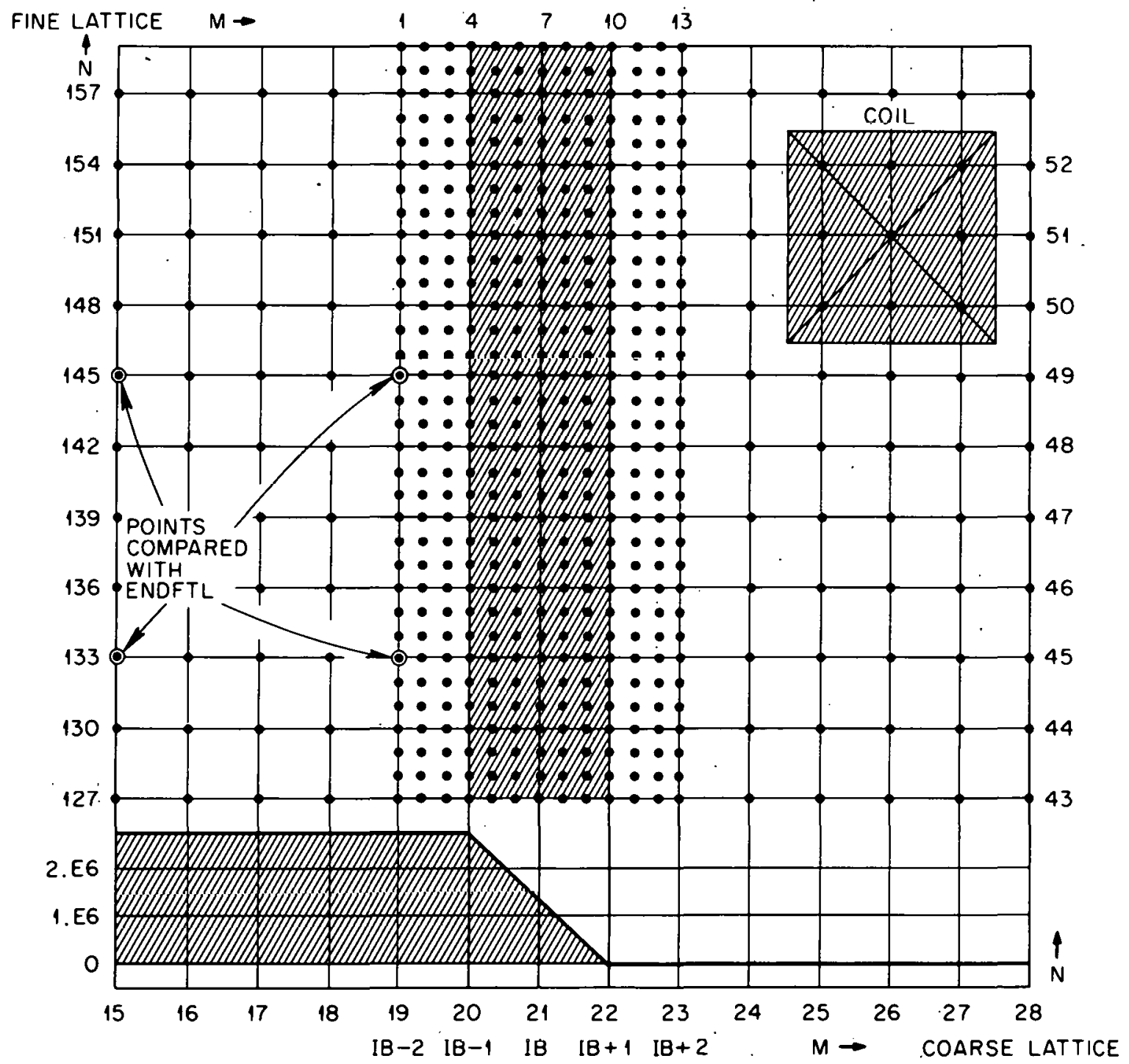

Fig. 2. Part of fine and coarse lattices. 


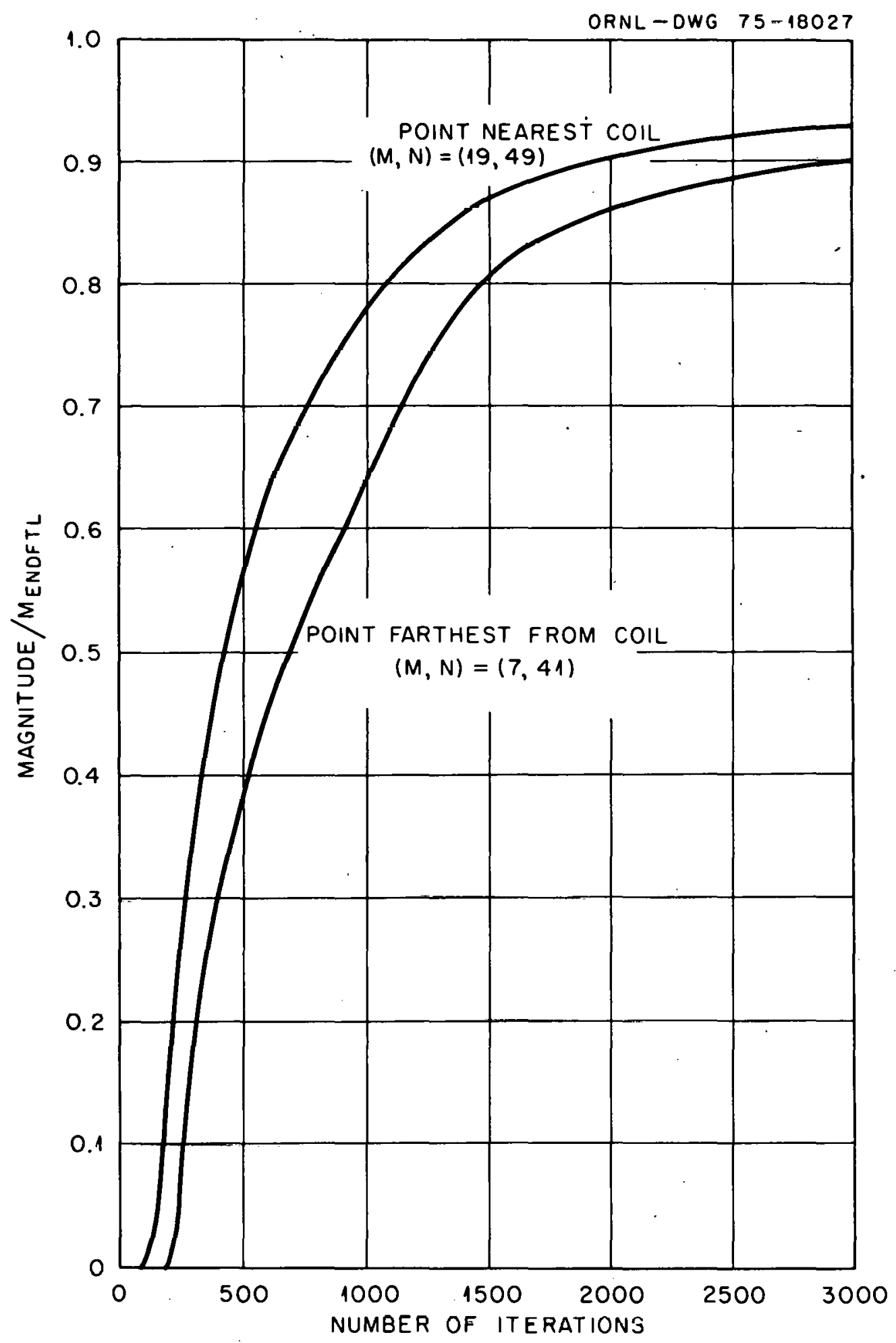

Fig. 3. Convergence of magnitude of vector potential. 


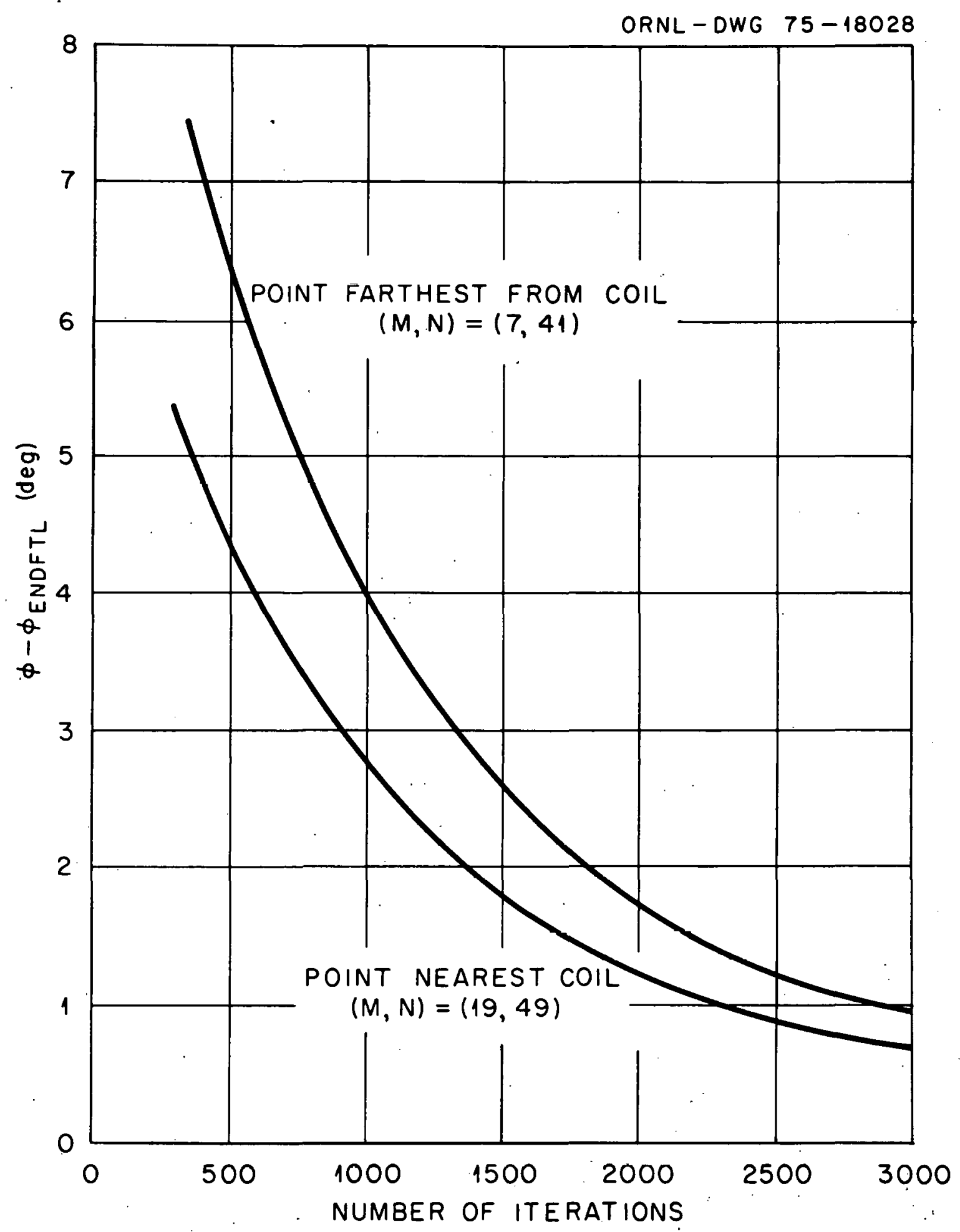

Fig. 4. Convergence of phase of vector potential. 
The COARSE subroutine sets the values of the vector potential at points which are one coarse lattice spacing inside the transition regions (in the fine lattice) equal to the value of the vector potential obtained at that point in the previous relaxation of the fine lattice. This is zero at the start, of course, but gradually builds up through successive iterations. Using these initialized values as fixed boundary values for the coarse lattice relaxation, plus zero values of the vector potential on the symmetry axis and around the outside of the whole lattice, the coarse lattice is relaxed. Each region with different properties, such as the metal, the coil, or air, is treated separately, of course. The quantity called CUR $=\mu /$ (cross-sectional area of the coil in lattice spacings) can be seen to be equal to the factor $\mu a^{2} J$ in Eq. (13) if the driving current $I$ is $1 \mathrm{~A}$. First we note that $H$ in the program has the same lattice spacing as the $\alpha$ in Eq. (13). Then

$$
\mu a^{2} J=\mu H^{2} J=\mu \frac{I}{\left(r_{2}-r_{1} / H\right)\left(\ell_{2}-\ell_{1} / H\right)}=\frac{\mu I}{n^{2}\left(R_{2}-R_{1}\right)\left(L_{2}-L_{1}\right)}=I * \mathrm{CUR},
$$

which becomes CUR when $I=1$. The actual driving current $I$ has been factored out as one of the scaling parameters. 'lhe coarse laftce points on the initialized boundary points are not changed. They are four fine lattice steps inside the fine lattice. At the end of each relaxation calculation, the changes are calculated in the values of the real and imaginary parts of the vector potential from the previous iteration, the values are "over-relaxed" by the constant $C C$, and the changes are added to the "SUM," which measures the progress toward convergence.

Then the main control program switches to the FINE subroutine, in which the fine lattice boundaries are initialized, and then the rest of the fine lattice is relaxed. The values of the vector potential at the boundaries are set equal to the values obtained for the coarse lattice in the previous stage. This is done directly for those fine lattice points which coincide with coarse lattice points, but values for fine lattice points between the coarse lattice points are obtained by a linear interpolation. Then the real and imaginary parts of the vector 
potential are relaxed and overrelaxed at each point in the fine lattice, except at the fixed boundary values, which overlap into the coarse lattice two coarse lattice steps.

When the process has converged sufficiently, as determined by the decrease in the value of SUM or by the limit imposed on the number of iterations, the program switches to the OUTPUT subroutine, which prints out the real and imaginary parts of the vector potential at various points in the coarse and fine lattices, near the region of the driving coil.

DETAILED -DESCRIPTION OF THE RELAX.F4 PROGRAM

\section{Main Control Routine}

The COMMON block specifications may need to be changed for different problems. At present the program is written for a cylindrical metal rod encircled by a rectangular cross-section coil in air, as shown in Fig. 1 . $A(M, N)$ and $B(M, N)$ are the real and imaginary parts of the vector potential in the coarse lattice, with 60 lattice indices along the radial direction in cylindrical coordinates and 101 lattice indices along the axial direction. $A F(M, N)$ and $B F(M, N)$ are the corresponding quantities for the fine lattice, which at present has 13 radial steps and 301 axial steps (three times as fine as the coarse lattice). $\operatorname{MAT}(M, N)$ and $\operatorname{MATF}(M, N)$ are matrices whose elements denote. the type of material at the point $(M, N)$ in the coarse and fine lattices respectively. $\operatorname{PERR}(N), \operatorname{PERZ}(N)$, and $\operatorname{COND}(N)$ specify combinations of the permeability along radial and $z$ directions and conductivity values at various points in the fine lattice. One may also want to change the data given in line 1300 , in order to keep track of the problem being solved.

The radius in the coarse lattice is $r=(M-1) a$, where $M$ goes from 1 to 60 arid $\dot{a}$ is the lattice spac1ng. We shall use just the index $M$ without the $a$ to express radial distances.

Various constants are defined as follows: 


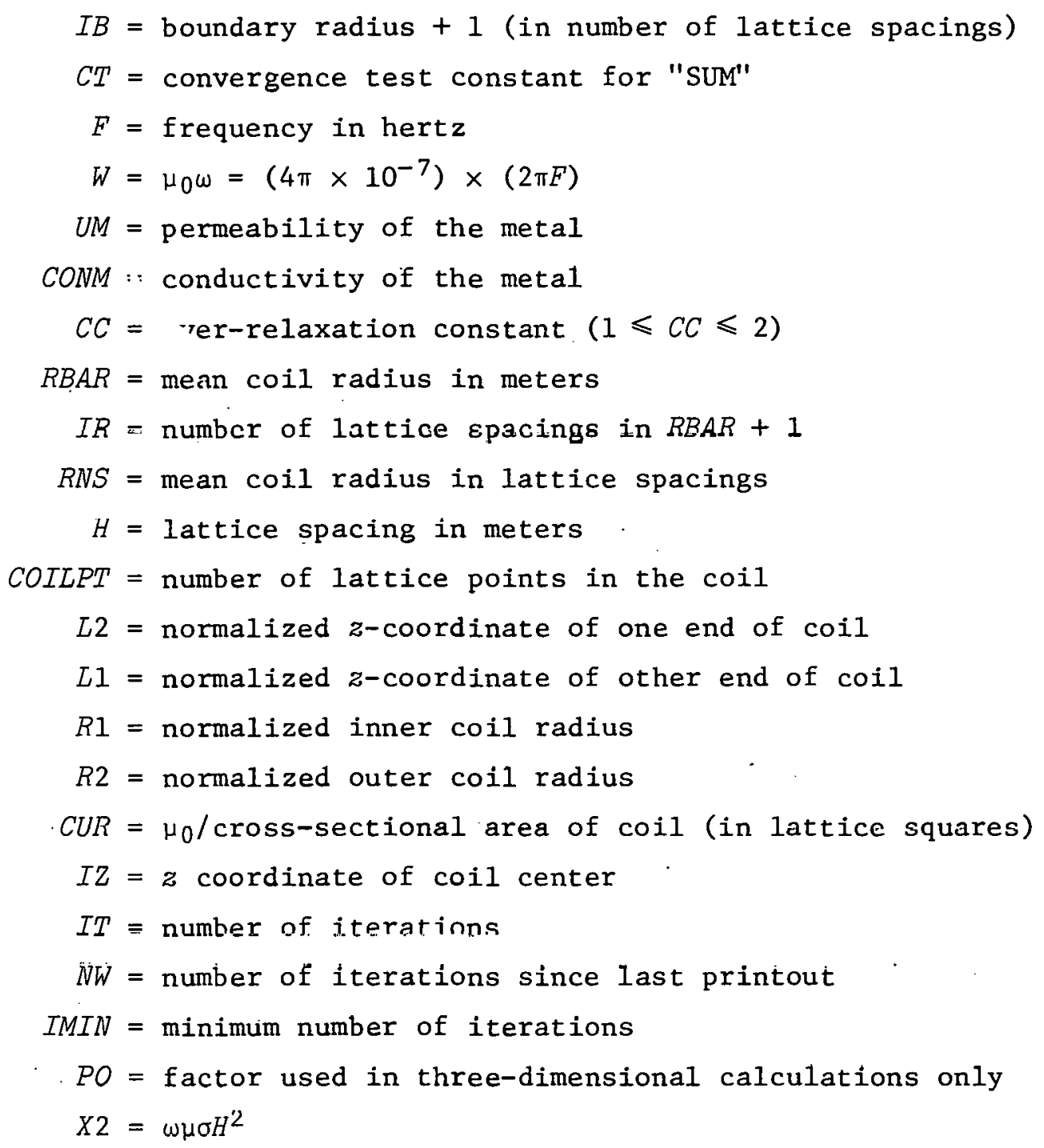

The program then produces a printout of some of the input parameters.

\section{LA'l'l Subroutine}

The LATT subroutine (1ines 27,000 through 35,500 ) first assigns numbers to the various regions in the problem in the form of a matrix $\operatorname{MAT}(M, N)$ : 0 represents the axis and the outer boundaries (which are never changed from zero vector potential); 1 represents the transition region (from metal to air); 2 represents the air region; 3 represents the coil region; and 4 represents the central metal rod. A map of the coarse lattice is then printed (1ines $31,600-32,400$ ). 
The fine lattice, described by $\operatorname{MATE}(M, N)$, is set up in a similar manner and is printed out in lines 34,300-35,100. The radial extent is from $M=1$ to 13, or 12 lattice spacings, while the axial extent is from $N=1$ to 301 , so that the fine lattice spacings are one-third the size of the coarse lattice spacings.

$\operatorname{PERR}(M)=\left(\mu_{M} / \mu_{M+1}-\mu_{M} / \mu_{M-1}\right) / 4$ is a function used in the relaxation calculations for a region with inhomogeneous permeability.

$\operatorname{COND}(M)=\omega \mu \sigma(H / 3)^{2}$, where $H / 3$ is the fine lattice spacing and $\sigma=\sigma(M)$ is a function of the radius $M$.

\section{COARSE Subroutine}

The convergence measure, "SUM," is first initialized to zero; then there is a DO loop which steps through the coarse lattice in the radial direction for all points inside the outer boundaries, which are left at zero vector potential. Then several quantities are defined which are used in the relaxation calculations:

$R I=a / r=$ inverse of radius in lattice spacings

$R H=R I / 2$

$X 1=4+(a / r)^{2}$

$X 3=1+(a / 2 r)$

$X 4=1-(a / 2 r)$

$I 1=$ radial index in the fine lattice which corresponds to the value of $M$ In the coarse lattice

$I 2=4$ = value of the axial index in the fine lattice where the initialization process starts, corresponding to the value $N=2$ in the coarse lattice; this is just inside the lower boundary, which is never changed from zero vector potential

The DU loop in line 11,600 causes the program to step through the coarse lattice in the axial direction for all points inside the boundary. 、 If the point. is in the transition region $[\operatorname{MAT}(M, N)=1]$, according to the test in line 11,800 , the relaxation process is bypassed, and the 
values of the $R Z$ and Im parts are initialized from the fine lattice in lines 13,500 and 13,600 .

Otherwise, the $R Z$ and $\operatorname{Im}$ parts of $A(R, Z)$ are calculated by the relaxation algorithm, using the expressions for $X 5$ and $X 6$. Lines 14,20014,400 make the calculation for air; lines 14,800-15,000 for the coil region; and lines 15,400-15,600 for the metal. The values found are overrelaxed in lines 16,200-16,500, and the convergence measure "SUM" is calculated in lines $16,600-16,700$.

\section{FINE Subroutine}

The fine lattice boundary values are initialized in lines 19,50020,800. The values at points coinciding with coarse lattice points àre calculated in lines 19,500-20,100. The $R Z$ and $I m$ parts at fine lattice points between the coarse lattice boundary points are set equal to values linearly interpolated between the values at the neighboring coarse lattice points.

In lines 22,600-23,200 the relaxation formulas for an inhomogeneous medium are applied and overrelaxed. The various quantities used in the relaxation are defined in lines $21,100-22,200$. The only one requiring further explanation is $A O R$, which is the reciprocal of the radius in fine lattice spacings. The radius must be measured from the central axis of the problem, not from $M=1$ in the fine lattice, and therefore $r$ is a fairly large number in terms of fine lattice spacings.

\section{OUTPUT Subroutine}

In lines 25,000-25,400 are instructions to print the vector potential in the coarse lattice for radii out to $M=30$ and; for $Z$ values from the center of the coil (where $N=51$ ) down to $N=40$. It is understood that the converged values are symmetrical about the coil center in this particular problem.

In lines $26,000-26,400$ are instructions to print the correspunding $R Z$ and $I m$ parts at fine lattice points from the coil midposition $(K=151)$ to $K=140$ for all values of the radial index $J$ (which goes from $J=1$ to 13$)$. 


\section{DISCUSSION OF MODIFICATIONS TO THE PROGRAM}

Several versions of the program have been tried with different values of the permeability of the central metal conductor, from $\mu=1$ to $\mu=200$.

A comparison of the accurate ENDFTL potentials and the RELAX results for a metal of unit permeability is shown in Table 1. The magnitudes are within $10 \%$ and the phases are within $1^{\circ}$ of the correct values at the lattice points with values of $M=7,11,15,19$ and $N=41,45,49$. Some of the disagreement may be caused by inexact matching of the ENDFTL and RELAX points of evaluation.

An extrafine lattice, twice as fine as the usual fine lattice, has also been tried for the case when the metal permeability is $\mu=4$. When compared with the "exact" values of the vector potential obtained from the ENDFTL program, the results are as shown in Table 2. The extrafine lattice gave magnitude errors only about one-third as large as those for the regular fine lattice, and the phases were about $7^{\circ}$ closer to the ENDFTL values. Thus it is evident that the extrafine lattice is a considerable improvement, and the lattice should perhaps be even finer. However, this is somewhat discouraging, since there are already almost as many points in the fine lattice as in the coarse lattice, and $\mu=4$ is a rather small permeability for a ferromagnetic medium. Presumably, for a larger permeability, an excessively fine lattice would be required to make the derivatives remain sufficiently small. From this standpoint, it now seems preferable to have only one layer of boundary points between media and use a separate set of boundary conditions for them, rather than using a "smooth" transition layer of inhomogeneous material to keep the derivatives small. The reason we used the transition layer approach. here was that we had the ultimate aim of making three-dimensional relaxations, in which the boundary conditions are coupled and quite complex, so that it still seems that the Inhomogeneous transition layer approach would be preferable for that sort of problem.

Probably some of the PRINT statements could be omitted. Among these are the ones for printing the map of the fine lattice. And the ones for printing IT and SUM could be moved from lines 7000-7100 tó 
Taisle 1. Domparison of ENDFT- and RELAX results for metal of uni= permeability :All nagritudes should be multiplied by $10^{-: 8}$; phases are in Jegrees)

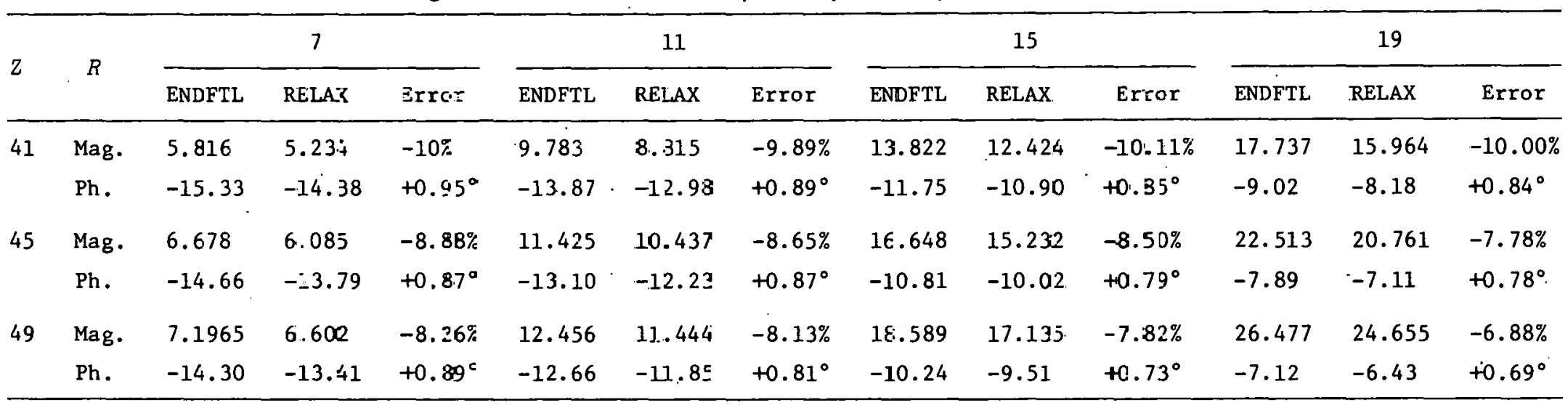

Tajle 2. Comparison of vector porential obtalned with ENbFTh and with LiLAX (F-ne lattice version of 4 Nov. 1975 and extrafine lattice version of 13 Nov. 1975" (s11 magnitudes shcu.d be mi.tififed by $10^{-6} ; \mu=4 ;$ phases are in degrees:

\begin{tabular}{|c|c|c|c|c|c|c|c|c|c|c|c|c|c|c|c|c|c|c|c|c|c|}
\hline \multirow[b]{2}{*}{2} & \multirow[b]{2}{*}{$R$} & \multicolumn{5}{|c|}{7} & \multicolumn{5}{|c|}{11} & \multicolumn{5}{|c|}{15} & \multicolumn{5}{|c|}{19} \\
\hline & & ENDFTL & $\begin{array}{r}\text { RELAX } \\
\text { fine }\end{array}$ & Error & $\begin{array}{l}\text { Extra- } \\
\text { fine }\end{array}$ & Error & ENDFTL & $\begin{array}{r}\text { RELAX } \\
\text { f1ne }\end{array}$ & Etrct & $\begin{array}{l}\text { Extrs- } \\
\text { fin? }\end{array}$ & Error & ENDFCL & $\begin{array}{r}\mathrm{REL}, 2 \mathrm{X} \\
\mathrm{f} \mathrm{i} \text {. }\end{array}$ & Error & $\begin{array}{l}\text { Extras- } \\
\text { fin: }\end{array}$ & Erres. & ENDFTL & $\begin{array}{c}\text { RELAX. } \\
\text { =ine }\end{array}$ & Error & $\begin{array}{c}\text { Exitra- } \\
\text { fine }\end{array}$ & Error \\
\hline \multirow[t]{2}{*}{41} & Mag. & 6.15 & 11.42 & $+85.9 \%$ & 7.90 & $+28 z$ & 10.22 & 19.33 & $+3 c .2 x$ & 13.37 & $30.8 \%$ & 14.23 & 27.66 & +94.48 & $19.2 \mathrm{~J}$ & +35. 28 & 18.18 & 36.66 & $+101.7 \%$ & 25.45 & $+40.0 \%$ \\
\hline & $\mathrm{Ph}$. & -4.19 & -44.89 & $-40 . \pi^{\circ}$ & -37.96 & $-33.7{ }^{\circ}$ & $-\Xi .81$ & -39.12 & $-3 E . \equiv 1^{\circ}$ & -32.32 & $-28.51^{\circ}$ & -3.26 & -30.64 & $-27.38^{3}$ & -23.35 & $-20.5 \varepsilon^{\circ}$ & -2.52 & -19.77 & $-17.25^{\circ}$ & $-i 2.97$ & $-10.45^{\circ}$ \\
\hline \multirow[t]{2}{*}{45} & Mag. & 8.45 & 13.01 & +53.98 & 5.34 & $+10.5=$ & 14.10 & 22.32 & $+2 \epsilon .1 \%$ & $=6.23$ & $+14.9 \%$ & 19.70 & 32.85 & $+66.7 x$ & 24.12 & $=22.45$ & $25: 34$ & 45.57 & $+79.8 \%$ & 33.70 & $+33.0 x$ \\
\hline & Ph. & -3.87 & -43.54 & $-39.6:^{\circ}$ & -36.85 & $-32.9 z^{-}$ & $-\$ .54$ & -37.54 & $-3 e \cdot 60^{\circ}$ & -30.30 & $-27.36^{\circ}$ & -0.20 & -28.75 & $-28.46^{\circ}$ & $-22 .: \Delta a$ & $-22.10^{\circ}$ & -2.22 & -17.75 & $-15.54^{\circ}$ & -11.73 & $-9.51^{\circ}$ \\
\hline \multirow[t]{2}{*}{49} & Mag. & 6.16 & 14.00 & $+127.2=$ & 10:22 & $+65.9=$ & $1 . .70$ & 24.16 & $+2 e .8 z$ & $: 7.93$ & $+1.3 \%$ & $25.0 ?$ & 36.45 & +45.76 & 27.43 & $-9.6 \Xi$ & 32.67 & 52.82 & +61.78 & 40.72 & $+24.6 x$ \\
\hline & Ph. & -4.19 & $-4 \overline{2} .63$ & $=38.4 n^{\circ}$ & -36.24 & $-32.05^{\circ}$ & $-\therefore 30$ & -36.59 & $-33 .=9^{\circ}$ & -30.20 & $-26.9^{\circ}$ & -0.27 & -27.62 & $-27.35^{\mathrm{c}}$ & 151.51 & $-21.3 i^{\circ}$ & -1.98 & $-16.2 p$ & $-14.29^{\circ}$ & -10.77 & $-8.79^{\circ}$ \\
\hline
\end{tabular}


lines $24,725-24,750$, with the print number changed from 60 , so that the number of iterations and the SUM would only be printed at the end of every 500 iterations.

In order to produce more rapid convergence, the overrelaxation constant, $C C$, could be increased from 1.0 to 1.5 or 1.75 . However, care must be exercised, since the immediate replacement of the old value with the new, relaxed value makes instability and oscillation somewhat more likely than with the usual relaxation procedure.

If a different geometry is desired, the COMMON block statements will need to be changed, as well as the LATT subroutine, the initializations in the COARSE and FINE subroutines, and the PRINT ranges in the OUTPUT subroutine. In fact, only the relaxation and overrelaxation algorithms can be carried over with any confidence, although the method of shifting back and forth to the fine lattice will still be valid and although it might be changed to shifting between boundary and nonboundary points.

USING THE PROGRAM ON A TIME-SHARING COMPUTER

The RELAX.F4 file may be read off the magnetic tape in the MONITOR mode with the command

FILE R, D622, RELAX.F4

If desired, it can then be left stored on the user's disk file. When sufficient time has elapsed for copying the file from the tape, then the commands

EDIT RELAX.F4

$. P 100: 5500$

will cause the firet 55 lines to be printed.

The input parameters are mostly located in the MAIN control routine and are explained in the comment line just preceding the parameter input. In the EDIT mode, one can just replace the data line by typing .R(1ine number) (carriage return) 
and then retyping the line with the correct data after the Teletype reprints the line number. Remember that there are six spaces after the line number before the parameter is given.

The dates in lines 200 and 1300 should probably be changed, so as to keep track of the version being run.

If the metal permeability, UM, is changed in line 2400, the DATA statement in line 27,900 should also be changed. It should start with four values equal to $U M$ and end with four values of 1.0 , with five intermediate values in between. For example, if $U M=4$., the DATA statement might be

DATA V/4*4., 3.5,3., 2.5,2., $1.5,4 * 1 . /$

If the fine lattice spacing is changed from its present one-third coarse lattice value, the number of intermediate data values must be increased. For example, if an extrafine lattice, twice as fine as at present, is used, there should be 7 values equal to $U M$, followed by 11 intermediate values, and ending with 7 values equal to 1 ., making a total of 25 data values instead of the present 13 .

Similarly, if the conductivity of the metal is changed from CONM = $2.8 E 6$ in line 2600 , the conductivity data in line 28,000 should also be changed, starting with 4 values equal to CONM, followed by 5 intermediate values, and ending with 4 values of zero. As before, if a different fine lattice spacing is used, a different number of data values will be required.

If it is not desired to have printouts evcry 500 iterations, but only at the end. then the $N W$ statements can be deleted (lines 5300, $7500,7600,7700,7800$ ) with the commands

D5 300

D7500:7800

The number of iterations can be changed by altering IMIN in line 5500. It should probably be at least 2500 (see Figs. 3 and 4), unless $C C$ is greater than 1. 
If one wants the results to be printed out on the Teletype terminal, instead of the line printer, one can change all the PRINT statements to TYPE. This is most easily done with TECO.

The program is set up for a rectangular coil centered at $[(I R-1) a, I Z a]$ encircling a metal rod of radius $(I B-1) a$, relative permeability $U M$, and conductivity CONM. For any other geometry, extensive modifications to the LATT subroutine, the COMMON blocks, and the initiali.zation procedures will be necessary.

Given in the appendix is a printout of a sample run for a central rod of relative permeability $U M=4$, conductivity $C O N M=2.8 \times 10^{6} \mathrm{mhos} / \mathrm{m}$, and radius of 20 lattice spacings, encircled by a coil of square cross section (three lattice numbers on a side); centered at a radius of 25 lattice spacings (radial index $=26$ ). The rest of the region is assumed to be air; the transition region extends from radial index 19 to 21 , and the fine lattice has spacings one-third as large as the coarse lattice. The coarse and fine lattice maps are printed out immediately after the program, followed by the values of SUM at various iterations.

The $R I$ and Im parts of the vector potential in the coarse and fine lattices near the coil are also printed out after every 500 iterations. The values of $M$, the radial index, are given at the left side and increase downward, while the axial index, $N$, is given at the top and increases to the right. The coil is centered at $M=27, N=51$ in the coarse lattice. The points in the coarse lattice which are compared with the ENDFTL values are located at $(M, N)=(7,41),(7,45),(7,49),(11,41),(11,45)$, $(11,49),(15,41),(15,45),(15,49),(19,41),(19,45),(19,49)$. The first point is the one farthest from the coil; the last is nearest the coil; these are the points for which data are plotted in Figs. 3 and 4 . At each of the points, the upper number is the real part of the vector potential, and the lower number is the imaginary part, in mksA units.

For determining eddy-current heating, forces, etc., only the values inside the metal are important, and they can be used to calculate other electromagnetic quantities of interest, as explained in an earlier report. 5

${ }^{5}$ C. V. Dodd and W. E. Deeds, Scaling Relations for Eddy Current Phenomena, ORNL-5077 (November 1975). 
As stated previously, the purpose of writing this two-dimensional relaxation program was to test the method of alternating between coarse and fine lattice relaxations for use in a three-dimensional unsymmetrical situation. In order to test the method, the program was written to duplicate a symmetrical configuration whose solution was accurately known. Therefore, the program has been specialized to the cylindrically symmetric encircling coil. If a more complicated, but still axially symmetric, problem is to be solved, almost the entire program needs to be rewritten. The relaxation calculations in the coarse and fine lattices will still be valid, but all of the initializing routines will probably need modification, and it is impossible to sajy in general whether it would be easter to initialize individual lattice points or to write subroutines to initialize various groups of points, as has been done here.

After all editing changes have been made, one can save them by typing

Q

and a carriage return. Then one can exit and remove the line numbers by typing

B

followed by a carriage return.

To run the program on the 360/91 from a Teletype terminal, one needs to type a job card, say. JOB.JCL as follows:

$/ /$ (job name) (space) JOB (space) (charge No.), '(hin designation)'

/*ROUTE (25 spaces) PRINT (space) LOCAL

$/ / *$ CLASS (space) CPU91 $=10 \mathrm{M}$, REGION $=360 \mathrm{~K}$

$/ /$ (space) EXEC (space) FORTHCLG, PARM.FORT = "XREF," PARM.GO = 'DUMP $=I^{\prime}$

//FORT.SYSIN (space) DD (space) $*=$ RELAX.F4

$1 *$

$1 /$

ENDINPUT

$* \mathrm{BR}:$ JOB. JCL 
After the computer returns with an EXIT and a period, then type

IBM (space) JOB.JCL

After the terminal stops responding to this, type

TO (space) DISPATCHER

Then the computer will come back with a number of questions to which you should type the answers, such as

JOB NAME: D

REGION SIZE: 360

PHONE NUMBER:

$:$

SEND IT: YES

Now you can finally sign off, if you wish.

\section{ACKNOWLEDGMENTS}

The authors would like to express their appreciation to the Superconducting Magnet Development Program of the Thermonuclear Division, Oak Ridge National Laboratory, for funding this program. We would also like to acknowledge the help and encouragement of $\mathrm{H}$. T. Yeh of the Thermonuclear Division, and W. A. Simpson and R. W. McClung of the Metals and Ceramics Division. The report was edited by R. B. Parker and typed by Ethel Lynn Cagle of ORNL Technical Publications Department. 


\section{PAGES 24 to 26 WERE INTENTIONALLY LEFT BLANK}




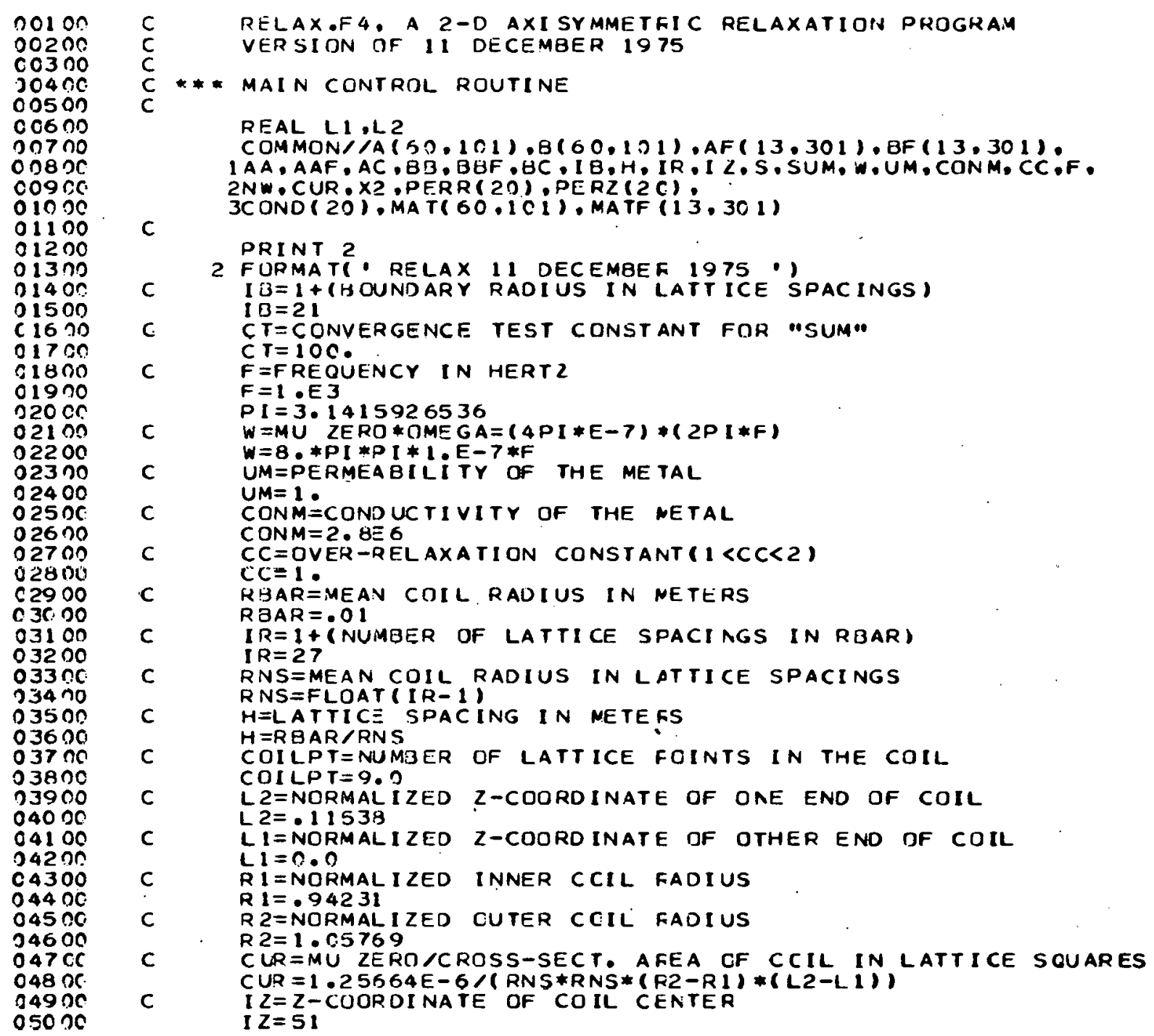




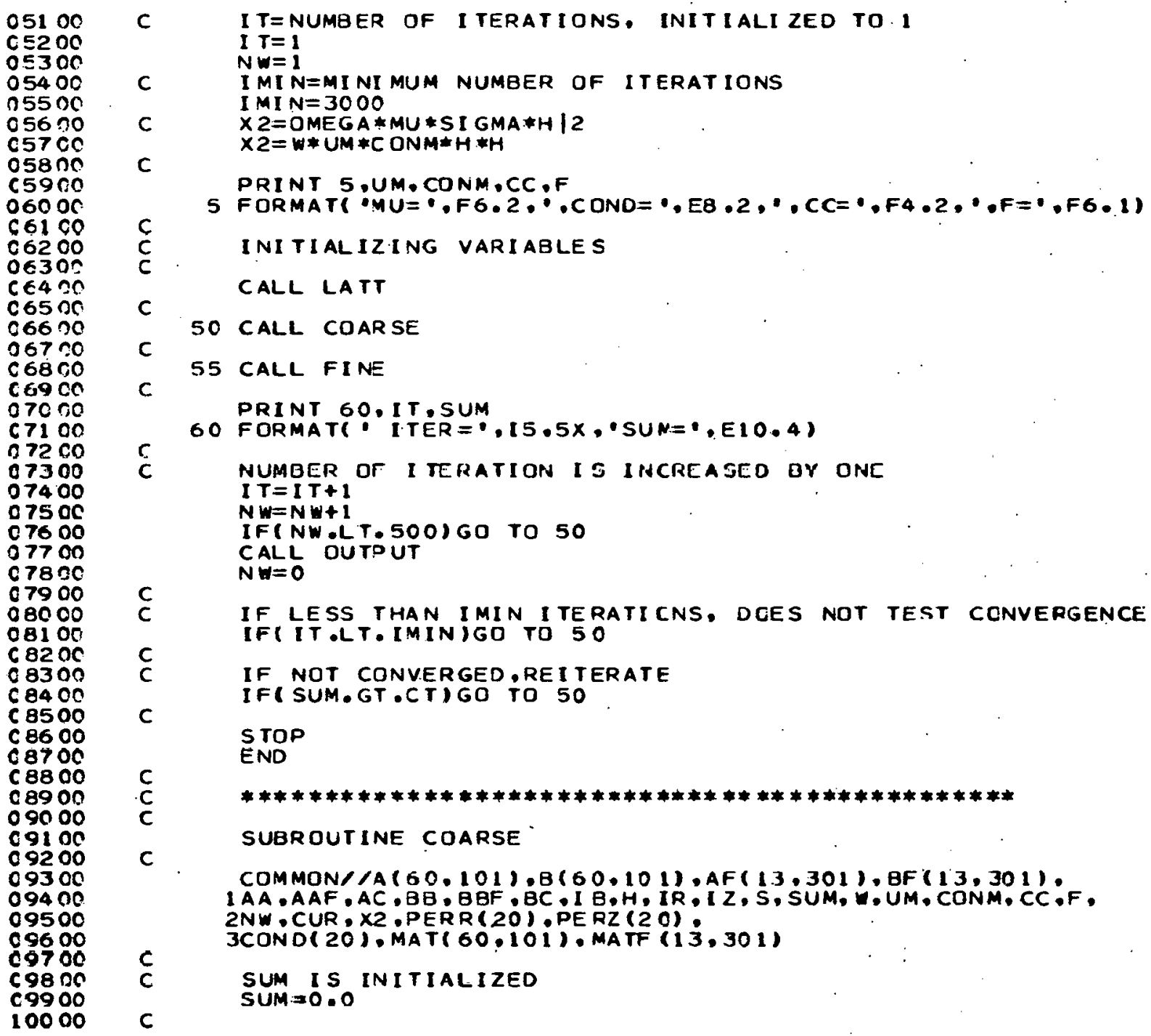




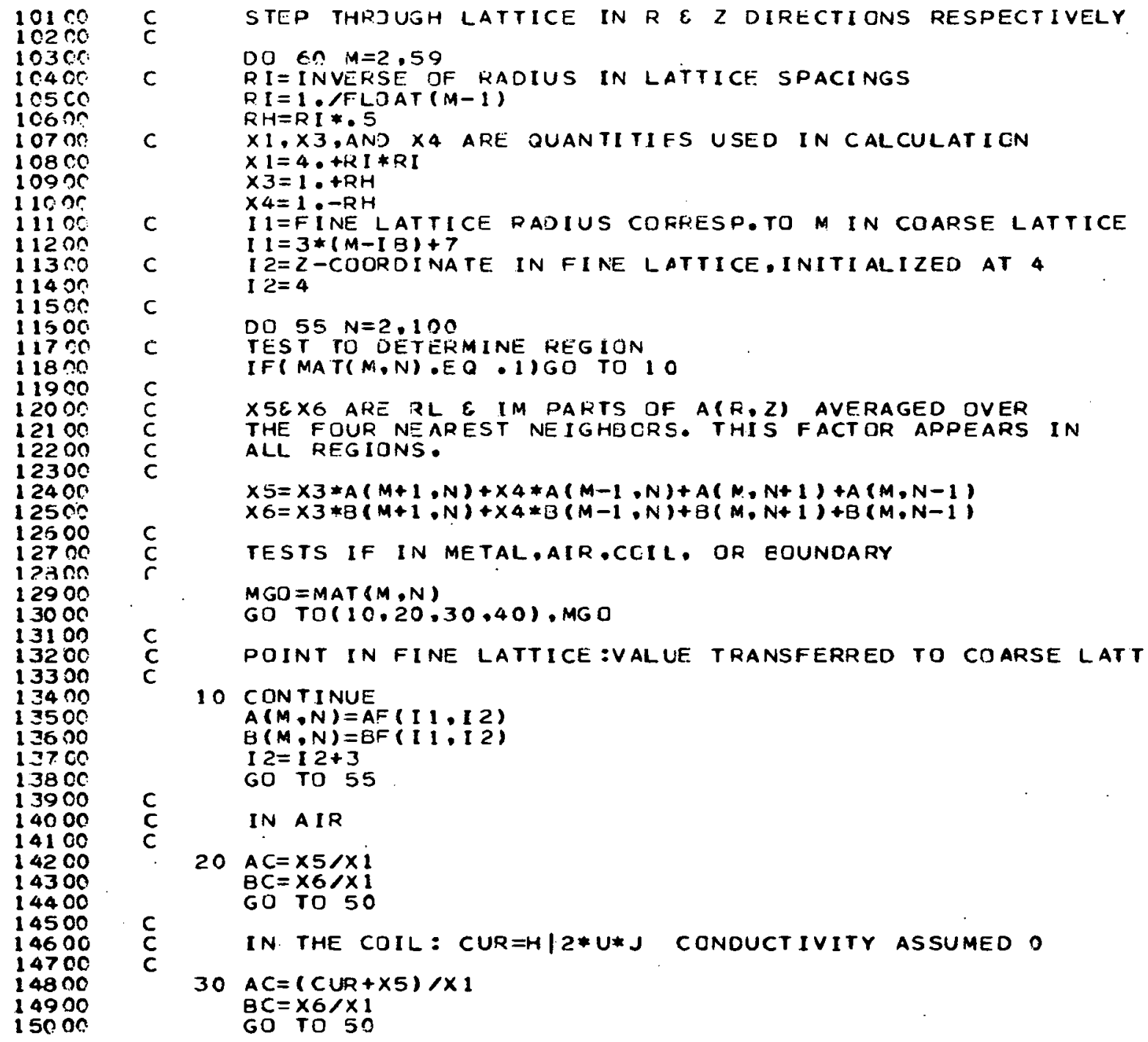




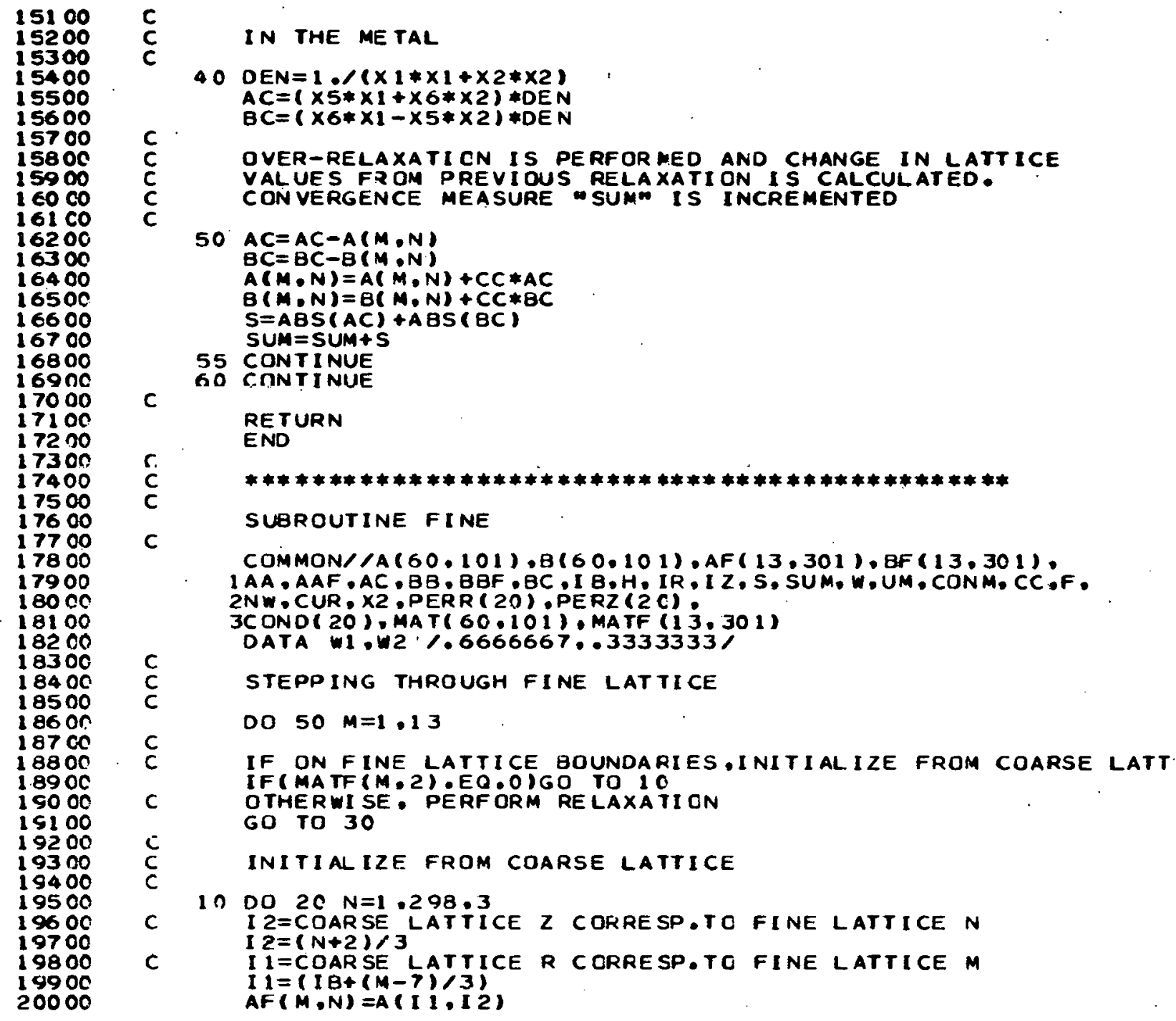




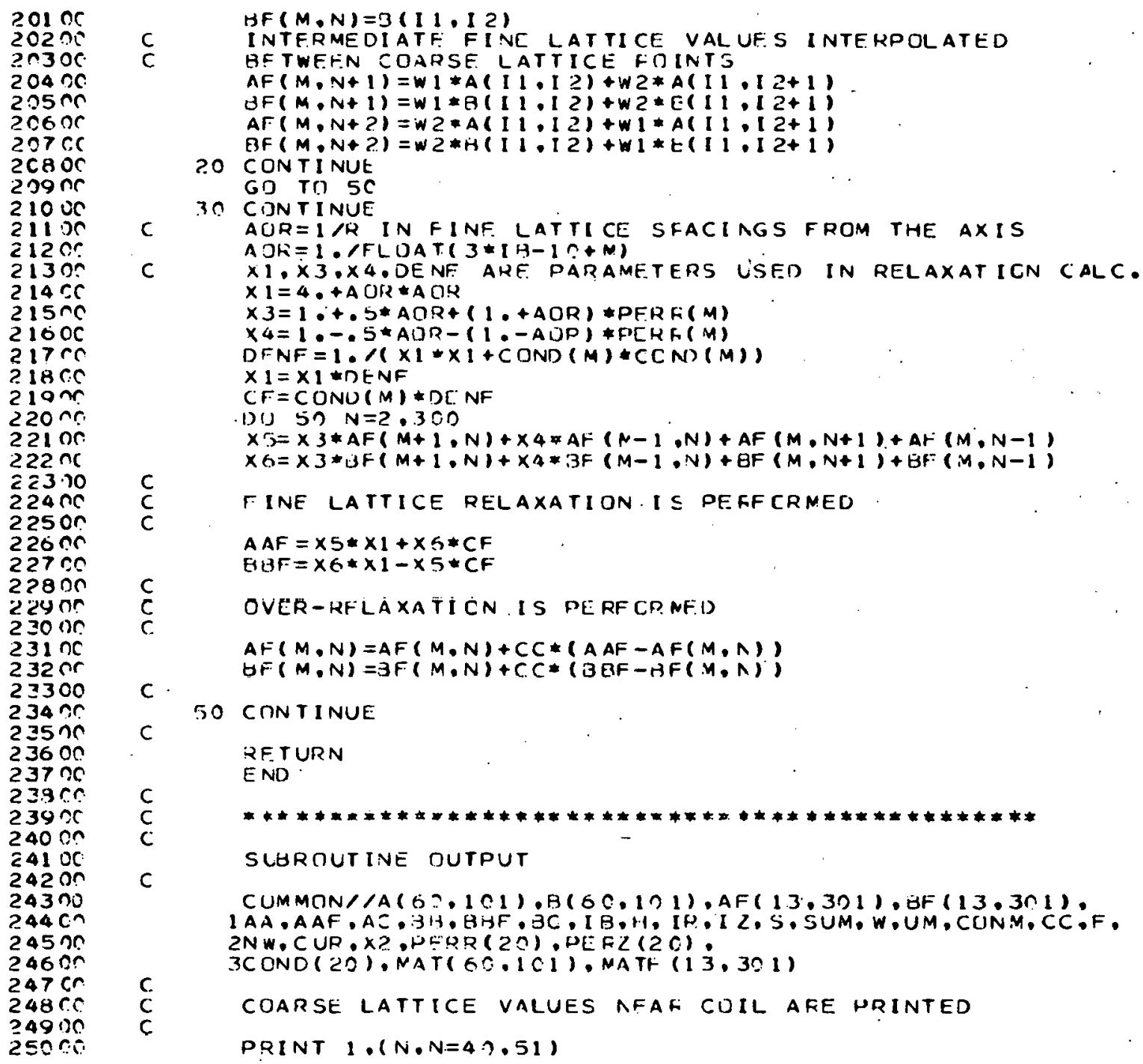




25100
25200
25300
25400
25500
25600
25700
25800
25900
26000
26100
26200
26300
26400
26500
26600
26700
26800
26900
27000
27100
27200
27300
27400
27500
27600
27700
27800
27900
28000
28100
28200
28300
28400
28500
28600
28700
23800
28900
29000
29100
29200
29300
29400
29500
29600
29700
29800
29900
30000
2

1 FCRMAT( $2 x \cdot 12110)$

DO $30 \quad M=2,30$

PRINT $10, M,(A(M, N), N=40.51),(E(*, N), N=40,51)$

10 FORMAT( I . 12.2X.12(E9.3:1X)/5X.12(E9.3,1X))

20 CONTINUE

C

30 CONTINUE

c. Fine lattice values near coIl are printed

PRINT $1,(K, K=140.151)$

DO $60 \mathrm{~J}=1,13$

PRINT 40.J.(AF $(J, K), K=140,151),(B F(J, K), K=140,151$ )

40 FORMAT $(0,1,12.2 X, 12(E 9.3 .1 X) / 5 X, 12(E 9.3,1 X)$ )

50 CONTINUE

$C$

60 CONTINUE

RETURN

END

$\stackrel{c}{c}$

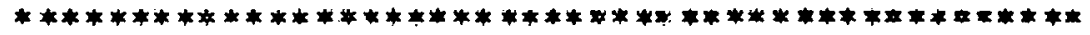

3UBROUT INSE LATT

COMMON/ $/ A(60,101), 3(60,101)$, AF (13,301), BF (13,301),

IAA,AAF,AC,BB, BBF,BC,IB,H,IR,IZ, S, SUM,W,UM,CONM,CC,F.

2NW, CUR, X2,PERR (20), PERZ $(20)$.

3COND(20).MAT $(60,101)$, MATF $(13,301)$

DIMENSI ON U (13). CON 13 (3)

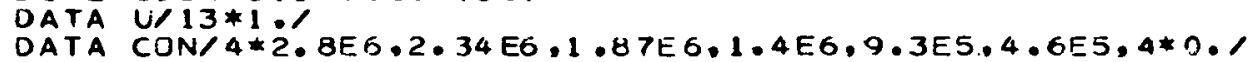

$C$
$C$
$C$
$C$
$C$
$C$
$C$
$C$

SET UP COARSE LATTICE

MAT(M.N) HAS THE VALUE O CN THE AXIS AND ARÓUNO THE

OUTER BOUNDARIES, WHERE THE VECTOR POTENTIÁL IS ALWAYS

KEPT ZERO: MAT(M,N)=1 FOR THE TRANSITION.REGION:

MAT $(M, N)=2$ IN THE AIR REG ICN: MAT $(M, N)=3$ IN/THE CCIL

REGION: ANO MAT $(M, N)=4$ IN THE CENTRAL MEFAL,RCO

DO $20 \quad M=1.50$.

DO $20 \quad N=1 \cdot 101$

$M A T(M, N)=C$

20 CUNTINUE

DO. $30 \quad N=2.100$

DO $25 M=2,19$

$\operatorname{MAT}(M, N)=4$

25 CONTINUE

DO $2 \epsilon \quad M=20.22$

$M A T(M, N)=1$

26 CONTINUE

DO $36 \quad M=23.60$ 


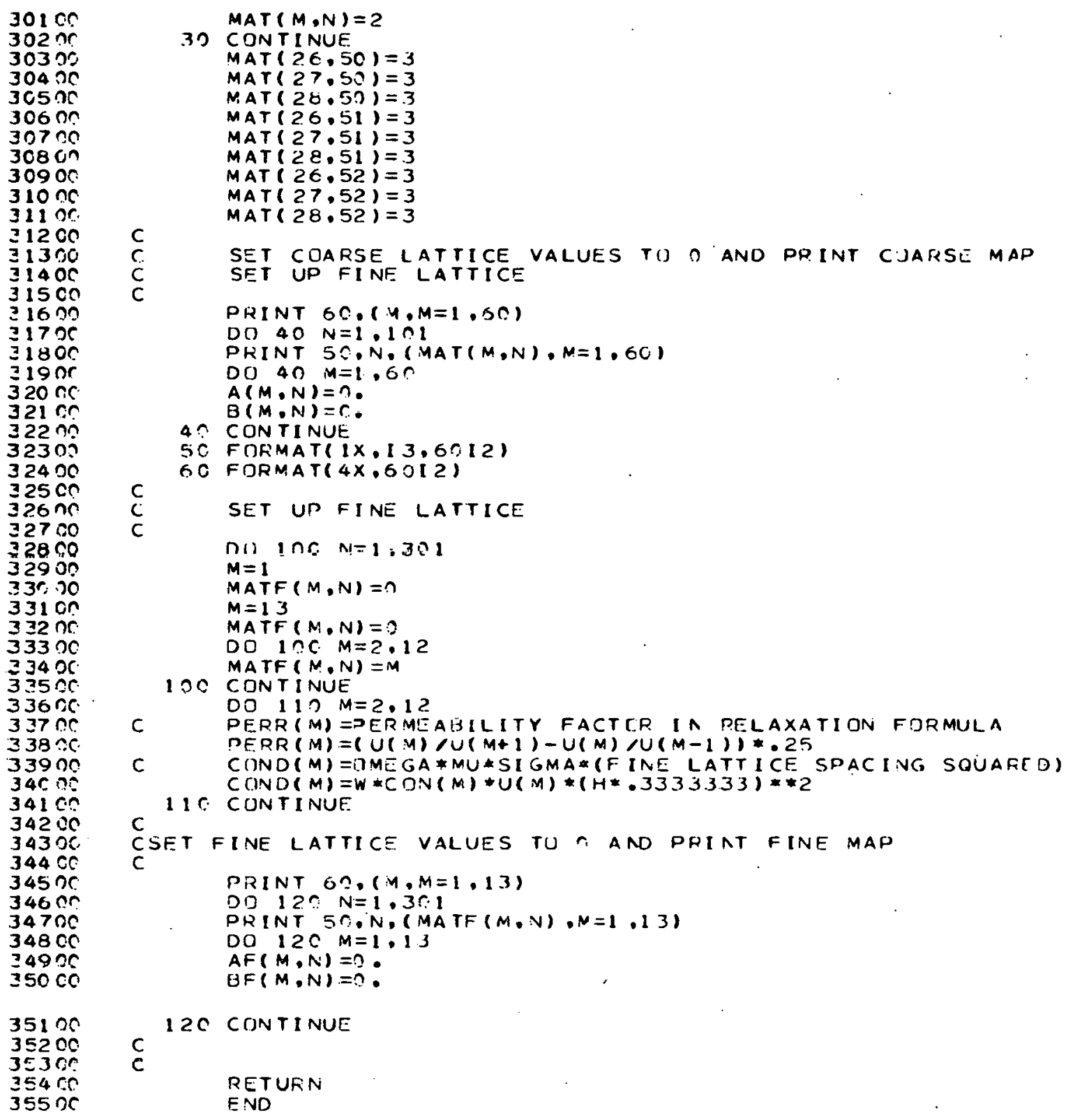




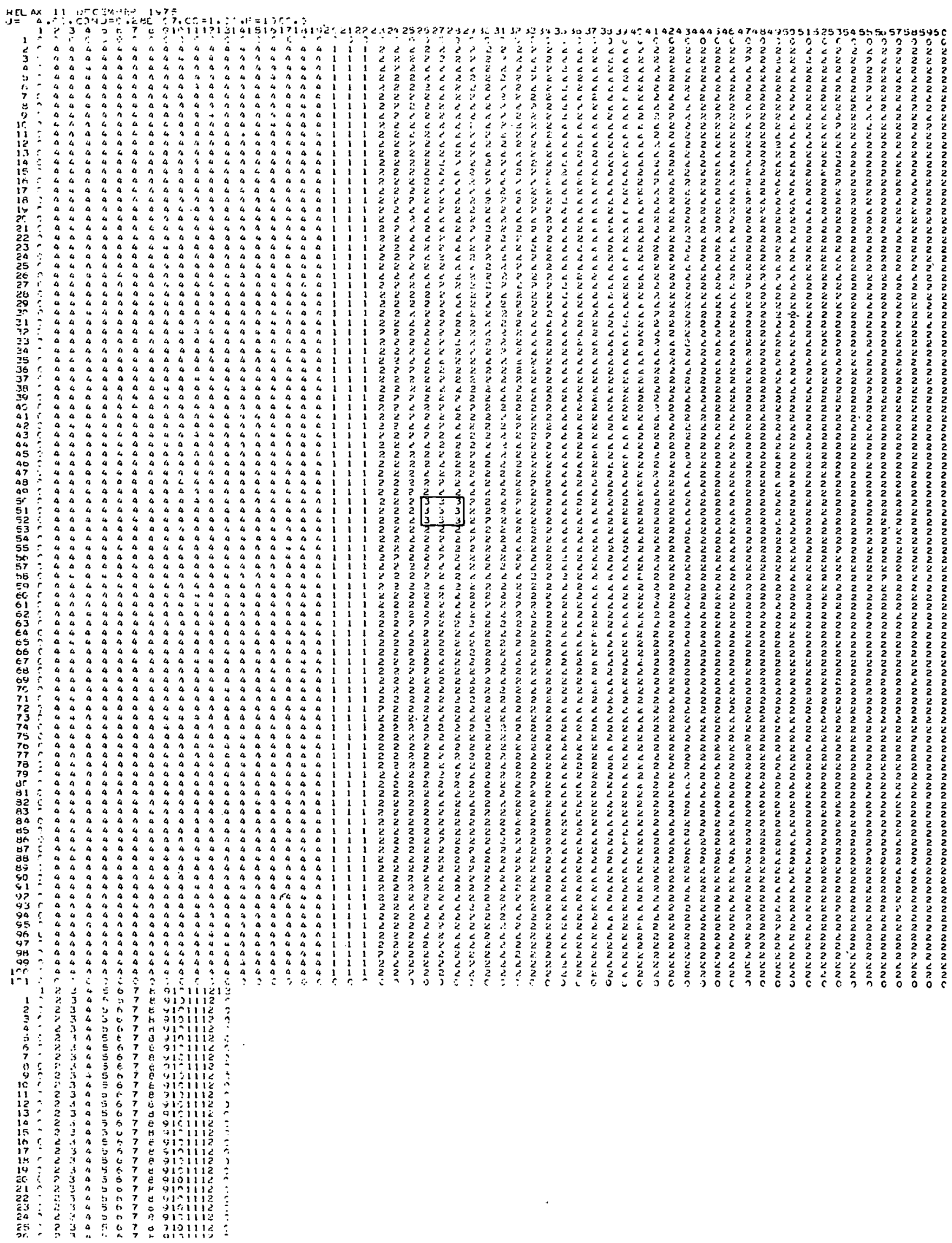




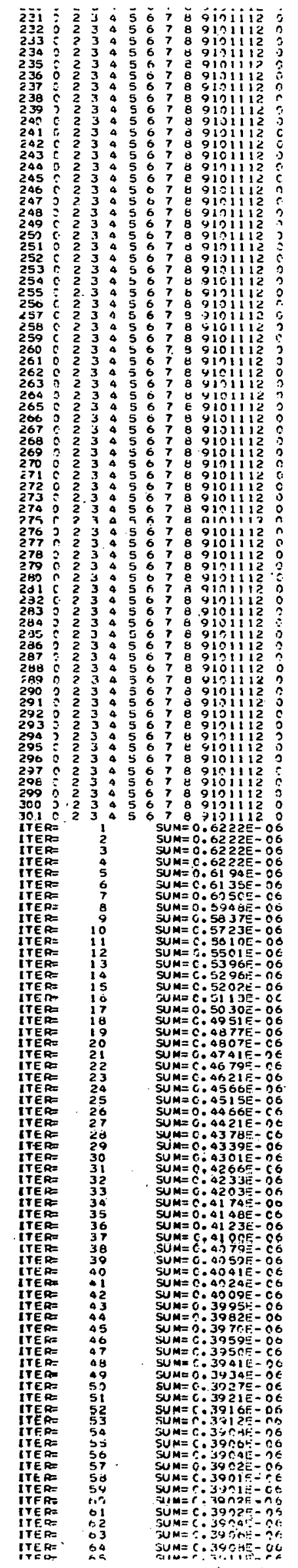



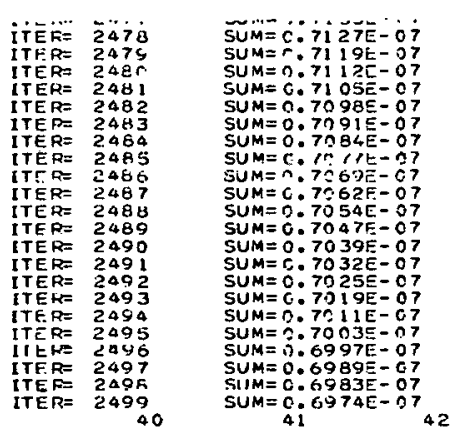

43

45

46

\section{7}

48

50

51

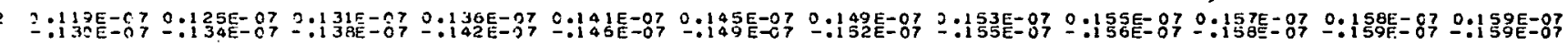

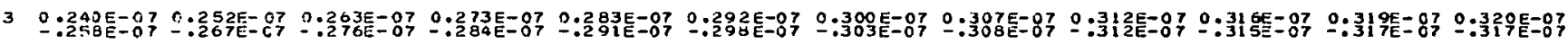

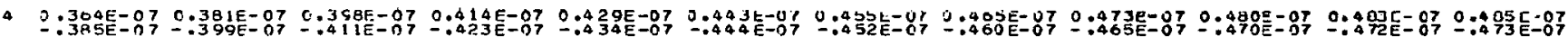

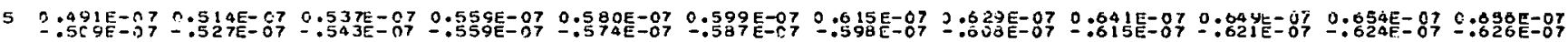

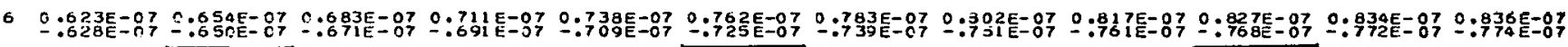

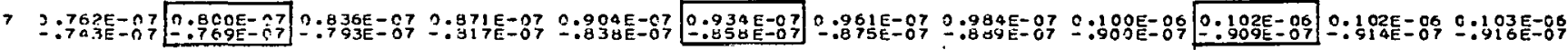

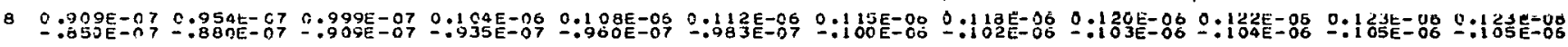

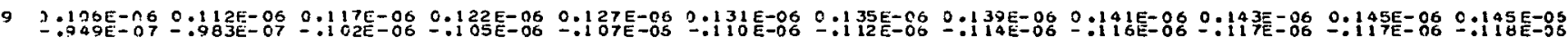

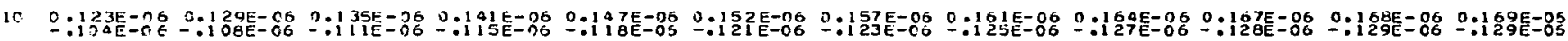

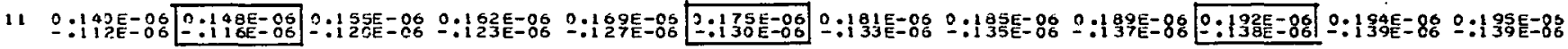

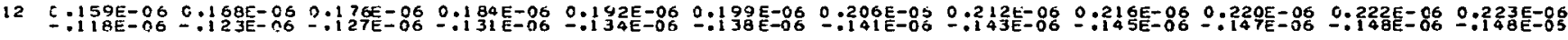

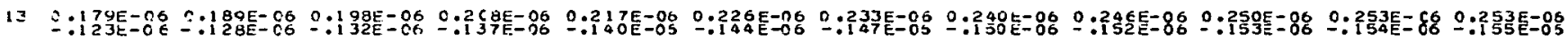

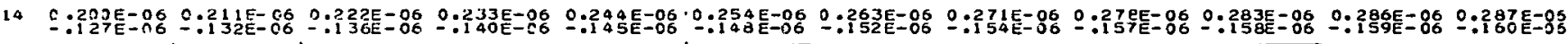

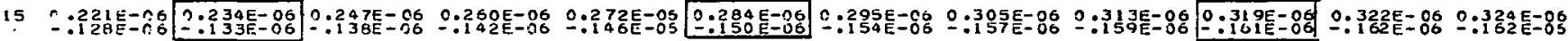

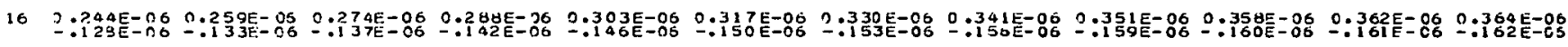

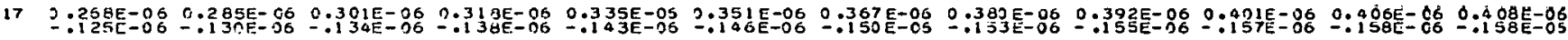

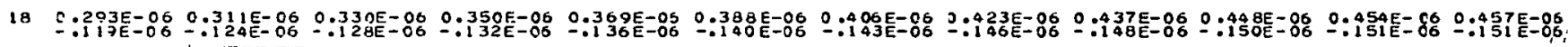

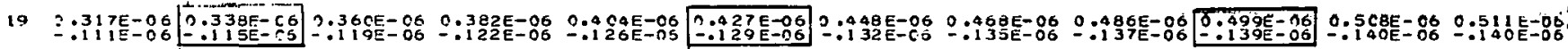

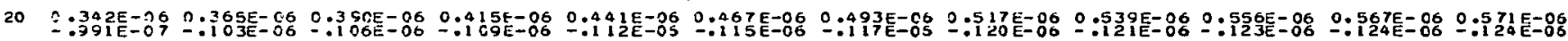

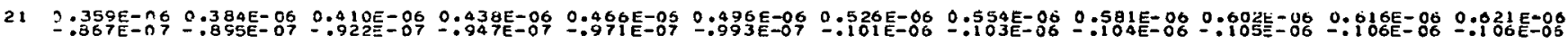

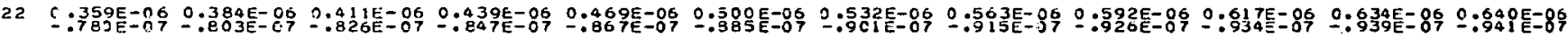

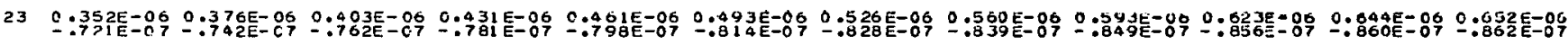

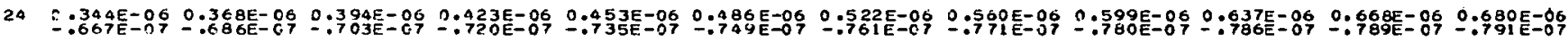

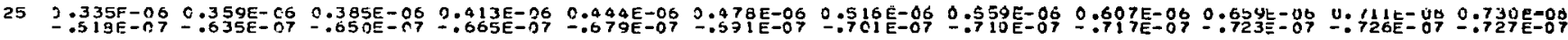

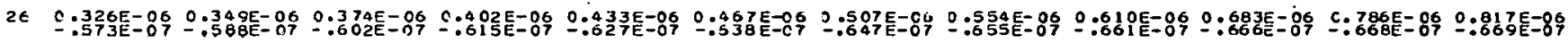

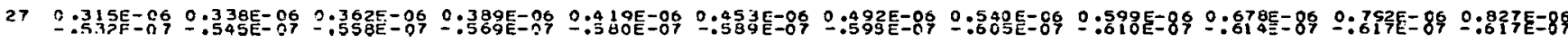

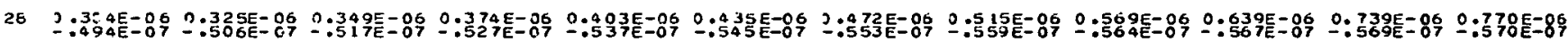

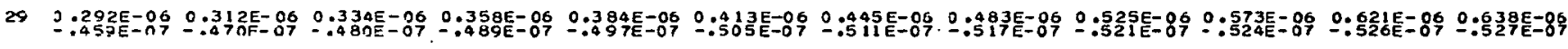

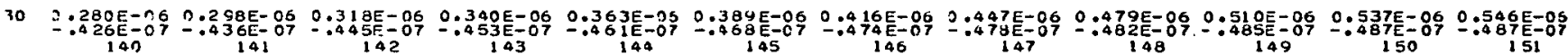

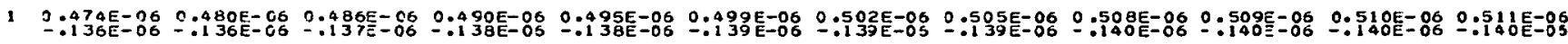

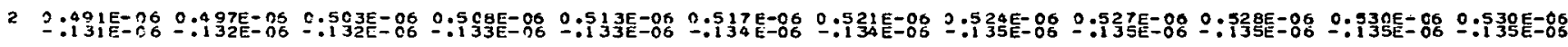

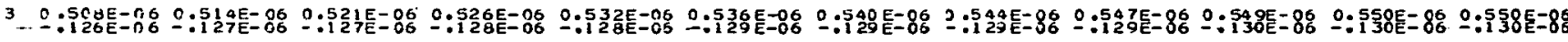

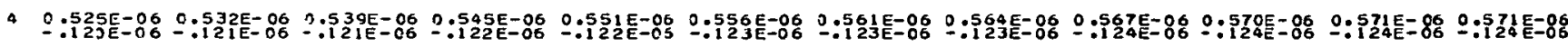

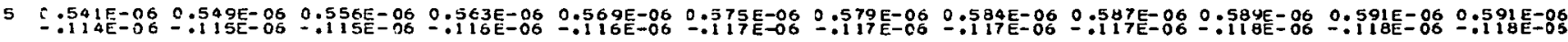

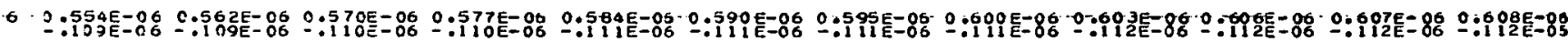

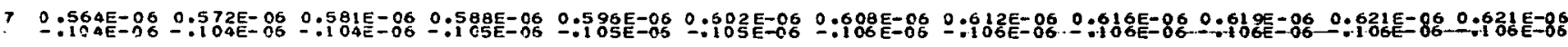

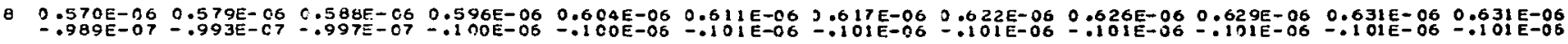




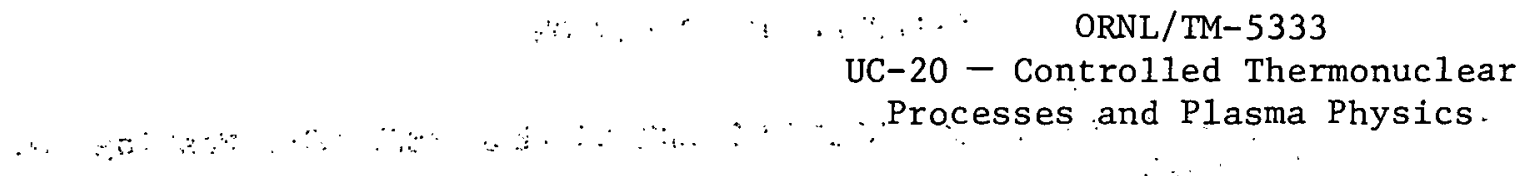

\section{INTERNAL DISTRIBUTION}

1-2. Central Research Library

3. Document 'Reference Section

4-6. Laboratory Records Department

7. Laboratory Records, ORNL R.C.

8. ORNL Patent office

9-10. Thermonuclear Library

11. W. C. Anderson

12. J. K, Ballou

13. R. L. Brown

14.* E.: H: 'Bryant

15. P." B. Burn

16. W. D. Cain

17. D. D. Cannon

18. J. F. Clarke

19. F. L. Culler

20. J. E. Cunningham

21. R. W. Derby

22-41. C. V. Dodd

42. G. W. Donaldson

43. L. Dresner

44. J. F. E11is

45. W. A. Fietz

46. A. P. Fraas

47. K. F. Froelich

48. W. H. Gray

49. P. N. Haubenreich

50. R. F. Hibbs

51-53. M. R. Hill

54. G. G. Kelley

55. C. G. Lawson

56. C. J. Long

57. H. M. Long

58. J. K. Lovin

59. M. S. Lubell

60. J. W. Lue

61. J. N. Luton
62. R. W. McClung

63. H. C. McCurdy

64. J. R. Miller

65. A. R. Moazed

66. O. B. Morgan

67. J. W. Pearce

68... H. Pih

69. H. Postma

70. M. Roberts

71. M. W. Rosenthal

72. R. E. Schwall

73. J. L. Scott

74. I. E. Shannon

75. S. S. Shen

76. J. E. Simpkins

77. W. A. Simpson

78. G. M. Slaughter

79. D. Steiner

80. J. 0. Stiegler

81. W.C.T. Stoddart

82. J. H. Smith

83. P. B. Thompson

84. D. B. Trauger

85. P. L. Walstrom

86. J. R. Weir

87. F. W. Wiffen

88. E. L. Woods

89. H. T. Yeh

90. A. Zucker

91. W. C. Leslie (consultant)

92. John Moteff (consultant)

93. Hayne Palmour III (consultant)

94. J. W. Prados (consultant)

95. N. E. Promisel (consultant)

96. G. V. Smith (consultant)

97. D. F. Stein (consultant) 
EXTERNAL DISTRIBUTION

98-99. USERDA DIVISION OF CONTROLLED THERMONUCLEAR RESEARCH, Washington, DC 20545

Director

100-101. USERDA OAK RIDGE OPERATIONS OFFICE, P. O. Box E, Oak Ridge, TN 37830

Director, Reactor Division

Research and Technical Support Diviston

102-293. USERDA TECHNICAL INFORMATION CENTER, Office of Information

Services, P. 0. Box 62, Oak Ridge, TN 37830

For distribution as shown in TID -4500 Distribution Category, UC-20 - Controlled Thermonuclear Processes and Plasma Physics 